\title{
Phonemic confusability, precategorical acoustic storage, and the suffix effect*
}

\author{
ROBERT G. CROWDER and CHAO-MING CHENG \\ Yale Lniversity. Vew Haven. Connecticut 06510
}

\begin{abstract}
Ss attempted ordered recall of acoustically presented strings of seven consonant-rowel sillables. In a control condition. each string was followed by a tone in presentation, while in the experimental (suffix) conditions. a verbal syllable followed the last to-be-remembered item. The independent variable was the phonemic similarity between the verbal suffix and the memory stimuli. Although the verbal syllables produced a large suffix effect as compared with the control condition. and although more errors were made overall when similarity was high. the degree to which the verbal suffix items reduced the recency advantage at the end of the series was independent of their phonemic similarity to the stimuli. This independence was taken as support for a distinction between acoustic and articulatory coding.
\end{abstract}

Crowder and Morton (1969) argued that each item in an acoustically presented memory-span test is held in two forms of coding shortly after its occurrence. one code based on the item's name (articulatory) and the other based on its sound (acoustic). Behavioral manifestations of the second code. which Crowder and Morton called precategorical acoustic storage. have been inferred from three experimental situations. In the first (Darwin. Turvey. \& Crowder. 1972). the S receives several simultaneous auditory messages followed by a visual cue indicating the spatial location of the single message he is being asked to report: Darwin et al found that if such a poststimulus cue occurs soon enough after the stimuli ( 1 or $2 \mathrm{sec}$ ). Ss can achieve substantially: better scores than when they must report the entire set of stimuli. The second manifestation of precategorical acoustic storage is in the comparison of immediate recall based on auditory presentation as opposed to visual presentation (see Crowder. 1972): here. the argument is that the advantage of auditory over visual presentation derives from the presence of extra information in the auditory case. which. in contrast to the precategorical store in vision. lasts long enough to be useful. The third experimental demonstration of precategorical acoustic storage is the stimulus suffix effect (Morton. Crowder.\& Prussin. 1971) produced by adding to acoustic input of a memory-span list an extra word after the final to-be-remembered item. Although this extra word is known in advance by the $S$ to be redundant. his inability to ignore it produces a selective decrement in recall for the last few serial positions. The idea is that precategorical acoustic storage is limited in its capacity and that the suffix word displaces information which would otherwise have been useful to the $S$ in retrieving the memory lists. Importantly. the modality effect and

*The present research was supported by NSI Grant (iB 15157 . We are grateful to Haskins Laboratories for providing facilities and computer time for preparation of stimulus materials. the stimulus suffix effect are performance differences located at the terminal end of the list. As has been explained in detail elsewhere (Crowder. 1972). the precategorical acoustic information is useful only for the terminal items: therefore. an operation designed to destroy this source of information is also effective only. for the terminal items. The present experiments explore the relationship between the suffix effect and the phonemic similarity of the suffix word to the memory items.

It is quite natural to wonder what the relation is between experiments on precategorical acoustic storage and the experiments initiated by the observations of Conrad (1964). Wickelgren (1965). and Sperling (1963) on what they call acoustic confusions. Working from evidence that memory items with phonemes in common tend to confuse with each other in ordered memory tasks. independent of the presentation modality. these authors and others have argued that short-term memory is supported by a code which is basically auditory. Is this acoustic code the same one substantially as the Crowder-Morton precategorical acoustic storage system? We are inclined to believe not. for two reasons. First. the stimulus suffix operation is ineffective when the memory list has been presented visually (Crowder \& Morton. 1969. Experiment II: Morton \& Holloway. 1970). Second. the size of the disruptive effect of the suffix appears to depend intimately on physical parameters of the suffix word. and how these parameters relate to the memory items. but not at all on cognitive-linguistic parameters (Crowder. 1972: Morton. Crow der. \& Prussin. 19711.

Here we present al converging type of evidence for the distinctness of the Crowder-Morton mechanisms from the form of coding which results in acoustic or more neutrally (see Wickelgren. 1969) phonemic confusion errors. If. as we maintain. the suffix effect occurs for reasons quite separate from whatever causes the phonemically similar letters h. s. d. g. p. and so on. to bo more difficult than the phonemically distinct letters $t . h$. 


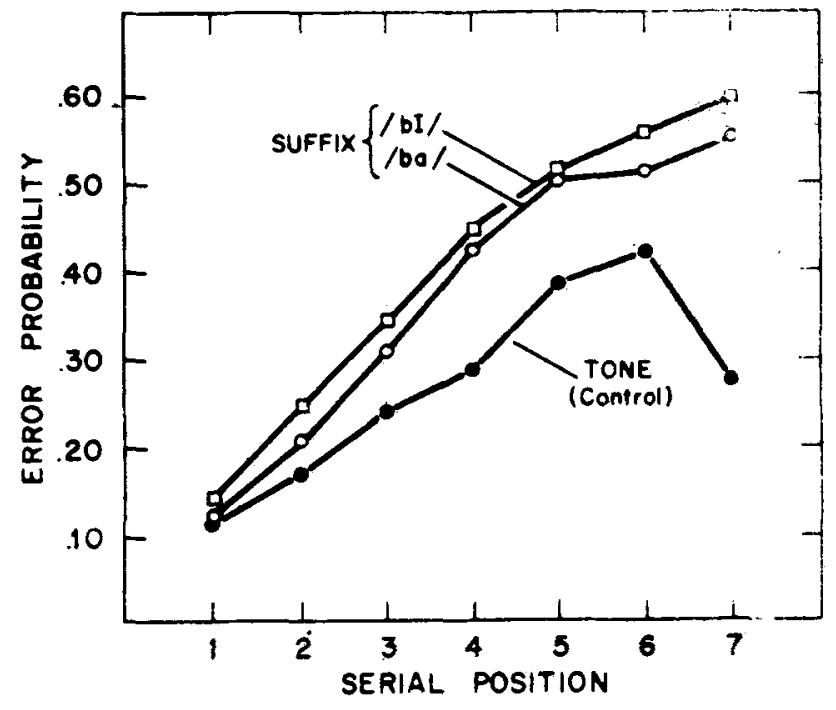

Fig. 1. The relation between serial position and error probability for the control condition. in which a tone followed the last item, and for two verbal suffix conditions, in which either $/ \mathrm{bl} /$ or $/ \mathrm{ba} /$ followed the last item.

j. k. 1, and so on. then it is reasonable to expect the suffix effect and the phonemic similarity effect to be sensitive to different variables. Specifically, the similarity along phonemic dimensions between the memory list and the suffix word should be unrelated to the size of the suffix effect. though it should quite possibly affect the overall recall level.

The view we wish to reject maintains that the situation is considerably simpler than suggested above. If there were a single auditory or speech-related code covering short-term memory from either modality. then the advantage of auditory over visual presentation could be ascribed to more direct access for auditory input to the fundamentally auditory store than for visual input. which would have to be recoded into auditory form. According to such a view, the suffix effect could be a special case of acoustic or phonemic confusion between neighboring items. If so. then it should be quite important how similar, along phonemic dimensions, the suffix and memory items are.

These contrasting expectations for the influence of phonemic similarity on the suffix effect were evaluated in the present experiment where Ss were responsible for remembering strings of seven consonant-vowel syllables taken from a three-item vocabulary-/gi. gI. gu/. Main interest was directed at the comparison of two suffix conditions distinguished by the degree of similarity to the memory items: these two suffix syllables were ${ }^{\prime} b I^{i}$ and $/ \mathrm{ba} /$. These are equally distinct from the memory items with respect to the redundant consonants /g! and $/ \mathrm{b} /$, but they differ with respect to the vowels. No single metric has been agreed upon for the purpose of representing vowel space: however. the present materials were chosen such that whichever convention is consulted (Flanagan, 1972: Hall. 1964: Pike. 1947: Sales. Haber. \&
Cole. 1968) $/ \mathrm{bI} /$ is maximally close to the three vowel sounds in the memory vocabulary, indeed it is identical with one of those sounds, and /ba/ is maximally distant from the three sounds. Sales et al have shown that these metric systems designed for vowels are not just constructions of linguists' imaginations but that they have psychological reality to the extent of predicting errors in immediate memory.

\section{METHOD}

Thirty paid college-age volunteers of both sexes received exactly the same fixed list of 50 seven-item memory stimuli. Each stimulus was a random selection and arrangement of the three syllables /gi. gI, gu/; no efforts were made to tamper with the results of random selection-even to the point that several stimuli contained only two of the three syllables. The memory syllables. and all other experimental materials, were produced on the Haskins Laboratories parallel resonance synthesizer and were automatically laid down on the test tapes by routines designed for use with a Honeywell DDP 224 computer. All utterances. with the exception of the ready signal, were $300 \mathrm{msec}$ in length. In the memory stimuli there was a $200-\mathrm{msec}$ silent period separating each item for a presentation rate of 2 items $/ \mathrm{sec}$. One second before each string. the word "Ready" occurred. and there was a 15 -sec recall period after each series. The five blocks of 10 trials were distinguished by what redundant sound occurred atter the last to-be-remembered item in each series. On the first. third. and fifth blocks, this extra sound was a $110-\mathrm{Hz}$ tone. defining the control condition. Previous investigations (Crowder. 1971, 1972) have shown that such a nonverbal sound does not have the effect of a verbal suffix and is thus an ideal control for timing. response preparation. and so forth. On the second and fourth blocks. the verbal suffixes $\mathrm{ba} /$ and $/ \mathrm{bl} /$ were used. half of the Ss hearing / $\mathrm{ba} /$ on the second block and half on the fourth block.

The $S s$ were tested in groups of from three to six. They were fully apprised of the redundant nature of the tone and verbal suffives and told to regard these as signals concerning when thet were allowed to begin w ritten recall. On the answer sheets provided. it was pointed out to the Ss that a space was indicated for each of the seven serial positions and that they should resist the temptation to depart from a strict left-to-right order in writing down their recalls. To minimize difficulties in comprehending the synthetic syllables, a number of examples of each was then played. following which a brief identification test was given.

\section{RESULTS}

Figure 1 gives the main result in terms of the relation between serial position and error probability. with the three experimental conditions the parameter. The general pattern is absolutely consistent with other research on the stimulus suffix effect. in particular with vocabularies in which the to-be-remembered information is contained in steady-state vowel sounds (Crowder. 1971). Thus. in the control condition. there was a statistically significant recency effect. as shown by the advantage of the last serial position over the next to last. Wilcoxon $T=19.5 . z=4.19 . p<.00005$. There was. however. no recency effect at all in either of the conditions where the last item was followed by a verbal suffix: indeed. performance on the last position was worse than on the preccding item. Further. the suffix caused significant increases in error probabilities. which were a 
steadily increasing function of serial position. For the condition in which $/ \mathrm{ba} /$ was the suffix. $\mathrm{T}=27.5 . \mathrm{z}=$ 4.22. $p<.00005$.

The purpose of the experiment was to determine whether there would be a larger suffix effect when the suffix item was similar to the to-be-remembered items. $/ \mathrm{bl} /$. than when it was relatively dissimilar to the to-be-remembered items, $/ \mathrm{ba} /$. The figure shows that indeed there were more errors on the last (and next-to-last) position when the suffix was /bl/ than when it was $/ \mathrm{ba} /$. However, even for the last two positions combirled. this difference did not achieve statistical significance. $T=143.0 . z=1.37 . p=.085$. Even if this weak comparison had been closer to conventional levels of reliability. however. it would be improper to conclude that the suffix etfect. as such. was larger with bl/than with $\mathrm{ba}$. This is because, as Fig. 1 shows. there were more errors at all serial positions with /bl/ than with / ba/. As has been spelled out with some care elsewhere (for example. in Crowder. 1970). the aspect of the suffix effect which is significant for making inferences about precategorical acoustic storage is the extent to which errors are selectively increased at late serial positions but not at early serial positions. The overall elevation of errors caused by interpolating $/ \mathrm{bl} /$ as opposed to 'ba' after the list is what would be expected from postcategorical mechanisms such as retroactive inhibition.

In fact. it is of great importarice that more errors occurred overall in the bl than in the / ba/ condition. becatuse otherwise the slaim could be advanced that these two suffix items did not represent a sufficiently. strong contrast in terms of similarity to the memory items to constitute a fair test of the major hypothesis. In terms of total recall failures. the Wilcoxon test gave a marginal result with regard to the comparison of the two verbal suffix conditions. $T=132.5 . z=1.61 . p=.054$. A different performance measure. however. the total number of seven-item strings perfectly recalled. gave a result of exactly the officially sanctioned strength. $\mathrm{T}=$ 76.0. $z=1.64 . \mathrm{p}=.05$. The means associated with this performance measure. of a possible 15 . were 0.90 and 1.47 eompletely correct strings for the $\mathrm{bl}^{\prime}$ and $\mathrm{ba}$; conditions, respectively.

\section{DISCUSSION}

We mar be assured. by the poorer overall performance with $b L^{\prime}$ as the suffix than with $b a$ as the suffix. that these two syllables were a sufficiently strong contrast in similarity to the memory vocubulary to affect behavior. This effect and its small magnitude numerically are quite consistent with extrapolations that can be made from Wickelgren's (1965) experiment. Where the similarity and number of interpolated items was varied following presentation of a to-be-remembered string. Although the mechunism througl which retroative inhibition oceurs is not understood. We take the position tiat such inhibition is occurring at a stage logically following perception of the items as linguistic units.

For reasons sketched above. evidence for interference at the precategorical acoustic level is adduced from performance changes which are specific to the end of the list. Since the differences observed between the two present suffix conditions were evident across all positions. we conclude that the suffix effect is not influenced by the similarity along phonemic dimensions of the suffix item to the memory items. Put differently. the essential argument is that the suffix effect constitutes a change in the shape of the serial position function. just the same change that occurs when visual and auditory presentations are compared. In the present study. both suffix items caused very large changes in the shape of the serial position function as compared with the control condition. where a tone followed the last item. However. there was no difference between the two verbal suffix conditions in terms of the shape of their serial position functions: only in their elevation were they different.

We are thus encouraged to believe that the phenomena that have been attributed to the effects of precategorical acoustic storage and phonemic confusion effects are occurring at different stages of information processing. Just how these separate stages may be related to one another will be an important question guiding efforts to understand the nature of each better than we do now. Keeping in mind. finally. that the validity of making some distinction between information processing stages is easier to establish than is the detailed nature of either of those two stages. it is tempting to return provisionally to our earlier conviction that the memory confusions based on phonemic similarity are articulatory in nature.

\section{REFERENCES}

Conrad. R. Acoustic confusions in immediate memory. British Journal of Psychology, 1964. 55. 75-84.

Crowder. R. G. The role of one's own voice in immediate memory. Connitive Pyychology. 1970. 1. 157-178.

Crowder. R. G. The sound of rowels and consonants in immediate memory. Johirmal of Verbal Learning \& Verbal Behavior. 1971. 10.587-\$96.

Crowder. R. G. Visual and auditory memory. In J. F. Karanagh and 1. G. Mattingly (Eds). Language by eye and ear: The relation between speech and learning to read. Cambridge: M.I.T. Press. 1972 .

Crowder. R. G.. \& Morton. I. Precategorical acoustic storage (PAS). Perception \& Psychophysics. 1969.5. 365-371.

Darwin. C. J.. Tuney. it. T.. \& Crowder. R. G. An auditor! analogue of the Sperling partial report technique: Fvidence for briaf anditory storige. Cognitive Psichology, 1972. 3. $255-267$

1:lamagan. J. L. Spech analysis sinthesis and perceprion. 12nd ad.) New lork: Springer-Verlag. 1972.

Hall. R. A.. Ir. Introductory linguistics. Philadelphia: Chilton Books. 1964. Pp. 76.97

Morton. J. Crowder. R. G.. \& Prussin. H. A. Evporiments with the stimulus uffis effect Joumal of Eyprimental Pridholog! Vonograph. 1971.91.169-190. 
Morton. J.. \& Hollowas. C. M. Absence of cross-modal "suffix effects" in short-term memory. Quarterly Journal of Experimental Psychology. 1970. 22. 167-176.

Pike. K. L. Phonemics: 4 technique for reducing languages to writing. Ann Arbor: University of Mfichigan Press. 1947. P. 5.

Sales. B. D.. Cole. R. A.. \& Haber. R. N. Mechanisms of aural encoding: $V$. Environmental effects of consonants on vowel encoding. Perception \& Psychophysics. 1969.6. 361-365.
Sperling. G. A model for visual memory tasks. Human Faitors. 1963. 5. 19-31.

Wickelgren. W. A. Acoustic similarity and retroacting inhibition in short-term memory: Journal of Verbal Learning \& Verbal Behavior. 1965, 4. 53-61.

(Received for publication September 13, 1972; accepted October 30.1972.) 